\title{
DIVERSIFICATION AND INTEGRATION AS A FORM OF PROVIDING STRATEGIC ORIENTATIONS OF ENTERPRISE MANAGEMENT
}

\author{
Yakub E. Dadaev \\ Chechen State University, Grozny, Russian Federation
}

\begin{abstract}
The article discusses the main views on understanding the strategy; levels of strategic enterprise management; the main types of strategies that can be implemented in the enterprise; classification of types of strategies. The author clarifies the interpretation of the essence of the concepts "goal", "landmark" and "development". The paper substantiates that the main (target) guideline of enterprise development management is to ensure its viability. Achieving this benchmark requires the implementation of a number of basic and specific benchmarks, which, together with the target, will constitute a system of strategic benchmarks. The essence of the concept of "diversification" is clarified; the motives, factors of the internal environment of the enterprise, which should be taken into account when choosing a diversification strategy are investigated; various classifications of diversification types are considered. Diversification is closely related to integration. The essence of the concept of "integration" is clarified, its forms, types, classifications, depending on certain characteristics are investigated. The place and role of diversification and integration in the strategic management of an enterprise, the criteria for the expediency of choosing and implementing a strategy are considered. It is concluded that diversification and integration are the most important tools for increasing the efficiency of the functioning of enterprises, increasing their viability and competitiveness, improving the financial condition and investment attractiveness. The purpose of the article is to expand the theoretical and methodological foundations of diversification and integration as forms of providing strategic guidelines for enterprise development management. The article determines that the strengthening of external and internal instability of the functioning of enterprises imposes new requirements on the choice and substantiation of the strategy and forms of providing strategic guidelines for managing the development of enterprises capable of ensuring viability and sustainable development.
\end{abstract}

Key words: diversification, integration, strategy, development, strategic management, enterprise, efficiency, economics.

Citation. Dadaev Ya.E. Diversification and Integration as a Form of Providing Strategic Orientations of Enterprise Management. Vestnik Volgogradskogo gosudarstvennogo universiteta. Ekonomika [Journal of Volgograd State University. Economics], 2021, vol. 23, no. 1, pp. 141-152. (in Russian). DOI: https://doi.org/10.15688/ ek.jvolsu.2021.1.12

\section{ДИВЕРСИФИКАЦИЯ И ИНТЕГРАЦИЯ КАК ФОРМЫ ОБЕСПЕЧЕНИЯ СТРАТЕГИЧЕСКИХ ОРИЕНТИРОВ УПРАВЛЕНИЯ ПРЕДПРИЯТИЕМ}

\author{
Якуб Элхазурович Дадаев \\ Чеченский государственный университет, г. Грозный, Российская Федерация
}


сущность понятия «диверсификация»; исследованы мотивы, факторы внутренней среды предприятия, которые должны учитываться при выборе стратегии диверсификации; рассмотрены различные классификации видов диверсификации. Диверсификация тесно связана с интеграцией. Уточнена сущность понятия «интеграция», исследованы ее формы, виды, классификации в зависимости от определенных признаков. Рассмотрены место и роль диверсификации и интеграции в стратегическом управлении предприятием, критерии целесообразности выбора и реализации стратегии. Сделаны выводы о том, что диверсификация и интеграция являются важнейшими инструментами роста эффективности функционирования предприятий, повышения их жизнеспособности и конкурентоспособности, улучшения финансового состояния и инвестиционной привлекательности. В статье определено, что усиление внешней и внутренней нестабильности функционирования предприятий предъявляет новые требования к выбору и обоснованию стратегии и форм обеспечения стратегических ориентиров управления развитием предприятий, способных обеспечить жизнеспособность и устойчивое развитие.

Ключевые слова: диверсификация, интеграция, стратегия, развитие, стратегическое управление, предприятие, эффективность, экономика.

Цитирование. Дадаев Я. Э. Диверсификация и интеграция как формы обеспечения стратегических ориентиров управления предприятием // Вестник Волгоградского государственного университета. Экономика. -2021. - Т. 23, № 1. - С. 141-152. - DOI: https://doi.org/10.15688/ek.jvolsu.2021.1.12

\section{Введение}

Анализ последних исследований и публикаций. Современный мир характеризуется трансформациями и глобальными изменениями в системе общественного производства, меняются векторы развития целых отраслей экономики под влиянием всеобъемлющей цифровизации и информатизации, внедрения новых технологий, усиливается конкурентная борьба на рынках, модифицируются механизмы производства и сотрудничества. Данные процессы происходят на фоне целого комплекса социально-экономических факторов, усложнения условий функционирования всех субъектов хозяйствования в целом и предприятий разных сфер деятельности в частности.

В условиях усиления как внешней, так и внутренней нестабильности функционирования предприятий необходимым условием их выживания и развития становятся верно выбранные стратегические ориентиры управления, способные обеспечить устойчивое развитие предприятия.

Обзор ранее выполненных исследований. Необходимо отметить, что проблематика стратегического менеджмента и управления развитием предприятия является достаточно широко исследованной в работах известных ученых: Р. Акоффа, Г. Альстренда, И. Ансоффа, К. Боумена, П. Друкера, Э. Майера, Р. Манна, Г. Минцберга, М. Портера,
А. Томпсона, А.Дж. Стрикленда, Д. Хана и др. В то же время сложность управления стратегическим развитием предприятий в условиях новых вызовов определяет наличие целого комплекса вопросов, требующих дальнейших исследований. Среди них - развитие теоретических основ управления развитием предприятия; совершенствование методических подходов к формированию стратегических ориентиров управления; обоснование выбора форм их обеспечения.

Цель работы. Целью статьи является расширение теоретико-методических основ диверсификации и интеграции как форм обеспечения стратегических ориентиров управления развитием предприятий.

Методология / методы. Исследование основывается на общенаучной методологии, которая предусматривает применение системного подхода к решению проблем. Основой данной работы являются научные труды отечественных и зарубежных ученых по вопросам диверсификации и интеграции как формы обеспечения стратегических ориентиров управления предприятием.

\section{Результаты и обсуждение}

Начало процесса стратегического мышления по управлению развитием предприятий приходится на середину XX века. Процесс эволюции теоретических основ стратегического управления продолжается в настоящее время. 
Я.Э. Дадаев. Диверсификация и интеграция как формы обеспечения стратегических ориентиров

В научной литературе по стратегическому планированию выделяются два основных взгляда на понимание стратегии:

1 - стратегия как конкретный долгосрочный план достижения некоторой цели, а выработка стратегии - как процесс нахождения некоторой цели и составление долгосрочного плана;

2 - стратегия как долгосрочное направлениеразвития предприятия, а также позиций предприятия в окружающей среде. Современные взгляды на управление развитием предприятия в основном базируются на втором подходе.

Стратегия разрабатывается и реализуется на всех уровнях стратегического управления предприятием: корпоративный, сферы бизнеса, функциональный, линейный [Стратегия - понятия и определения].

В теории стратегического управления выделяются четыре основных типа стратегий, которые могут быть внедрены на предприятии:

- стратегия концентрированного роста (стратегия усиления позиций на рынке, стратегия развития рынка, стратегия развития продукта);

- стратегия интегрированного роста (стратегия обратной вертикальной интеграции, стратегия вертикальной интеграции);

- стратегия диверсифицированного роста (стратегия центрированной диверсификации, стратегия горизонтальной диверсификации);

- стратегия сокращения (стратегия «сбора урожая», стратегия сокращения расходов).

Для предприятий, которые уже работают на рынке, занимают определенную рыночную нишу и стремятся к усилению своих рыночных позиций, особого внимания заслуживают стратегии интегрированного и диверсифицированного роста.
В настоящее время в теории стратегического управления существует огромное количество классификаций видов стратегий в зависимости от различных классификационных признаков. Наиболее распространенные из них приведены в таблице 1.

Стоит отметить, что препятствующим фактором классификации стратегий развития предприятия является то, что подавляющее количество из них не может быть однозначно отнесено к одному из признаков. Следовательно, существует большое количество различных авторских подходов к определению классификаций видов стратегий.

Стратегия является основным инструментом достижения целевых стратегических ориентиров управления развитием предприятия. В этом контексте целесообразно определиться с толкованием сущности понятий «цель», «ориентир» и «развитие», в том числе в контексте стратегического управления.

Слово «цель» ( $\tau \varepsilon \lambda \circ \varsigma)$ нередко в философских учениях толкуется как «завершение», «конец». Современные взгляды на сущность данного понятия сводятся к пониманию цели как того, к чему стремятся и чего пытаются достичь [Концепты. Гуманитарный портал].

Развитие является одной из важнейших категорий теоретико-методологического базиса стратегического управления предприятием. В целом многообразие взглядов ученых на понятие «развитие» можно представить в виде четырех групп:

- первая группа ученых связывает развитие с реализацией новых целей, целенаправленностью изменений;

- вторая рассматривает его как процесс адаптации к окружающей среде;

Таблииа 1

\section{Классификация стратегий развития предприятия}

\begin{tabular}{|l|l|}
\hline \multicolumn{1}{|c|}{ Классификационный признак } & \multicolumn{1}{|c|}{ Виды стратегий } \\
\hline По уровню управления & $\begin{array}{l}\text { Корпоративная; деловая; функциональная; ресурсная; опера- } \\
\text { тивная }\end{array}$ \\
\hline $\begin{array}{l}\text { По стадии жизненного цикла } \\
\text { предприятия }\end{array}$ & $\begin{array}{l}\text { Стратегия роста; стратегия стабилизации; стратегия сокраще- } \\
\text { ния; стратегия реструктуризации }\end{array}$ \\
\hline По характеру поведения на рынке & Активная; пассивная \\
\hline По рыночной позиции & $\begin{array}{l}\text { Стратегия лидерства по затратам; стратегия широкой диффе- } \\
\text { ренциации; стратегия оптимальных затрат; стратегия рыноч- } \\
\text { ной ниши (сфокусированная стратегия); стратегия предубеж- } \\
\text { дения (создание потенциала опережения конкурентов) }\end{array}$ \\
\hline
\end{tabular}

Примечание. Разработано автором на основе: [Ансофф, 1989; Мескон и др., 2006]. 
- третья - подменяет развитие его источником - противоречиями системы;

- четвертая - отождествляет развитие с одной из его линий - прогрессом, или усложнением систем, либо одной из его форм эволюцией [Ерохина, 2000].

Стратегическое управление развитием предприятия заключается в создании необходимых условий для количественно-качественных преобразований, направленных на предупреждение формирования противоречий.

С понятиями «стратегия» и «цель» тесно связано понятие «ориентир». Наиболее распространенным толкованием понятия «ориентир» является указатель направления действий, отдаленный целью, которую предприятие стремится достичь путем разработки и реализации стратегии.
Как отмечает И. Ансофф, стратегия и ориентиры при всем своем кажущемся сходстве являются совершенно разными понятиями. Ориентир близок по значению к цели, а стратегия является средством реализации цели. Ориентир является более высоким уровнем принятия управленческих решений, чем цель [Ансофф, 1989].

Ориентиры могут быть выражены как количественно, так и качественно. Д. Гут и Р. Тагири предложили композицию из шести основных направлений качественных ориентиров, которые могут быть использованы при стратегическом планировании организаций (табл. 2), а Х. Боссель - базовые ориентиры организации как системы (табл. 3).

Качественные ориентиры организации (Д. Гут и Р. Тагири)

Таблица 2

\begin{tabular}{|l|l|l|}
\hline \multicolumn{1}{|c|}{ Ориентиры } & \multicolumn{1}{|c|}{ Категория ценностей } & \multicolumn{1}{|c|}{ Типы целей } \\
\hline Теоретические & Истина, знание, рациональное мышление & Долгосрочные исследования и разработки \\
\hline Экономические & $\begin{array}{l}\text { Практичность, полезность, накопление бо- } \\
\text { гатства }\end{array}$ & Рост, доходность, результаты \\
\hline Политические & Власть, признание, рациональное мышление & $\begin{array}{l}\text { Общий объем капитала, продаж, количест- } \\
\text { во работников }\end{array}$ \\
\hline Социальные & $\begin{array}{l}\text { Человеческие отношения, привязанность, } \\
\text { отсутствие конфликта }\end{array}$ & $\begin{array}{l}\text { Социальная ответственность, благоприят- } \\
\text { ная атмосфера в организации }\end{array}$ \\
\hline Эстетические & $\begin{array}{l}\text { Художественная гармония, состав, форма и } \\
\text { симметрия }\end{array}$ & Привлекательность, этика \\
\hline
\end{tabular}

Примечание. Разработано автором на основе: [Мескон и др., 2006].

Таблица 3

Базовые ориентиры организации как системы (Х. Боссель)

\begin{tabular}{|c|c|}
\hline Ориентиры & Характеристика \\
\hline \multicolumn{2}{|r|}{ Обусловленные окружением } \\
\hline Существование & $\begin{array}{l}\text { Система должна быть совместима с нормальным состоянием окружения и способна } \\
\text { существовать в этом окружении }\end{array}$ \\
\hline Свобода действий & $\begin{array}{l}\text { Система должна обладать способностью разнообразными способами справляться с } \\
\text { требованиями, предъявляемыми к ней окружением }\end{array}$ \\
\hline Безопасность & $\begin{array}{l}\text { Система должна быть способной защитить себя от неблагоприятных воздействий из- } \\
\text { менчивости окружения }\end{array}$ \\
\hline Эффективность & $\begin{array}{l}\text { Борьба за сохранение ограниченных ресурсов (информационных, материальных, энер- } \\
\text { гетических) }\end{array}$ \\
\hline Адаптированность & $\begin{array}{l}\text { Система должна быть способной к обучению, адаптации и самоорганизации, с целью } \\
\text { выработки более адекватных способов реагирования на требования окружения }\end{array}$ \\
\hline $\begin{array}{l}\text { Совместное суще- } \\
\text { ствование }\end{array}$ & Система должна быть способной к модификации своего поведения \\
\hline \multicolumn{2}{|r|}{ Обусловленные системой } \\
\hline Репродуктивность & Самовоспроизводящиеся системы должны быть способны к развитию \\
\hline $\begin{array}{l}\text { Психологические } \\
\text { потребности }\end{array}$ & Коллектив организации, обладающий психологическими потребностями \\
\hline Ответственность & $\begin{array}{l}\text { Сознательные субъекты несут ответственность за свои поступки и должны подчинять- } \\
\text { ся нормативным требованиям }\end{array}$ \\
\hline
\end{tabular}

Примечание. Разработано автором на основе: [Боссель, 2001]. 
Я.Э. Дадаев. Диверсификация и интеграция как формы обеспечения стратегических ориентиров

Разнообразие классификаций ориентиров управления развитием обусловлено общей сложностью предприятия как системы, а также сложностью внешней среды его функционирования. Главным ориентиром управления развитием предприятия, по мнению автора статьи, является обеспечение его жизнеспособности, при этом надежность, устойчивость и другие ориентиры выступают своего рода составляющими жизнеспособности, отражающими разные аспекты предпринимательства. Итак, можно выделить целевой ориентир, базовые и специфические ориентиры, которые все вместе составят систему стратегических ориентиров. Специфические ориентиры должны быть развитием базовых ориентиров в зависимости от миссии предприятия, его структуры, специфики, внешнего окружения и других факторов.

Стратегия любой предпринимательской структуры должна быть динамичной и обновляться по мере развития. Потребность в изменениях появляется тогда, когда менеджмент видит пути улучшения существующей стратегии или возникает необходимость привести стратегию в соответствие с новыми рыночными условиями. В этом случае, прежде всего, необходимым является пересмотр стратегических ориентиров управления развитием предприятия, а также форм их обеспечения, среди которых важнейшее место занимают диверсификация и интеграция.

Слово «диверсификация» происходит от латинского «diversificatio» - изменение, разнообразие, латинского «diversus» - различный и «facere» - делать. В современной научной литературе наблюдается разнообразие подходов к толкованию понятия «диверсификация», в одних отражается деятельность предприятий различных сфер производства, в других акцент делается либо на необходимости достижения целей (в частности, снижение риска потери дохода и капитала), либо на средства достижения этих целей.

Среди распространенных подходов к толкованию понятия «диверсификация» можно выделить следующие:

- расширение номенклатуры продукции, производимой отдельными предприятиями, которая существует в двух основных формах: расширение ассортимента товаров; выход за пределы основного вида деятельности;

- одновременное развитие нескольких или многих взаимосвязанных технологических видов производства или обслуживания, расширение ассортимента производства и услуг предоставления; стратегия, которая предусматривает вход предприятия в новые для него сферы бизнеса;

- стратегический механизм структуризации хозяйственной деятельности, что предусматривает расширение, распределение и развитие связанных или несвязанных между собой элементов экономической системы с целью распределения рисков, максимизации экономического блага, достижения целей и эффекта синергии;

- вектор развития, который позволяет предприятию открывать для себя неосвоенные сферы деятельности через внедрение инноваций;

- процесс появления новых форм и направлений деятельности предприятия, в результате чего достигается минимизация рисков и формируется эффективная структура управления;

- осуществление деятельности субъектами хозяйствования на основе перераспределения ресурсов, что имеет целью производство новых товаров, используя новейшие технологии, проникновения на новые рынки;

- стратегический процесс (перераспределение ресурсов в отличные сферы деятельности по сравнению с существующими), форма организации предпринимательской деятельности (интеграция, кооперация, специализация, концентрация) [Стрелков, 2008].

Итак, в обобщенном виде диверсификация представляет собой стратегию развития предприятия, предусматривающую одновременное вложение капитала в развитие многопрофильного бизнеса. Основными мотивами выбора такой стратегии в условиях нестабильности внешней среды функционирования предприятия является стремление не зависеть от единственного или ограниченного круга поставщиков сырья, технологий и комплектующих; одного или нескольких однотипных видов продукции / услуг; единого рынка сбыта; ограниченного круга покупателей на локальном рынке и т. п. 
В научной литературе предлагаются различные классификации видов диверсификации, наиболее распространенными среди которых являются следующие (табл. 4 и 5).

Также ученые предлагают другие виды классификаций в зависимости от различных классификационных признаков:

- по критерию сферы деятельности выделяют три формы диверсификации: производственную, финансовую и маркетинговую;

- по среде осуществления - внутреннюю и внешнюю;

- по степени взаимосвязи - родственную и неродственную;

- по объекту - экономической деятельности, производства, номенклатуры и ассортимента продукции, капитала, кадров, размещения;

- по типу экономического развития - экстенсивную и интенсивную;
- по целям - стратегическую и тактическую;

- по величине субъектов - крупного предпринимательства, среднего предпринимательства и малого предпринимательства и др. [Сафрончук, 2017].

Необходимо отметить, что классификация видов диверсификации по признакам является достаточно условной, все виды экономической диверсификации взаимосвязаны, следовательно, при реальном осуществлении диверсификационных процессов достаточно сложно четко отделить определенные виды диверсификации друг от друга.

На практике предприятие может внедрять и смешанную стратегию, которая проявляется в комбинировании вышеприведенных видов диверсификации, каждый из которых имеет определенный набор преимуществ и рисков. Но в любом случае в основе опреде-

\section{Классификация видов диверсификации по форме}

Таблица 4

\begin{tabular}{|l|l|}
\hline \multicolumn{1}{|c|}{ Виды диверсификации } & \multicolumn{1}{|c|}{ Особенности } \\
\hline $\begin{array}{l}\text { Конгломератная (многоот- } \\
\text { раслевая) }\end{array}$ & $\begin{array}{l}\text { Представляет собой расширение ассортимента предприятия продукцией, не } \\
\text { имеюей никакого отношения к технологиям, используемым им, а также к его } \\
\text { продукции и рынкам сбыта. Такой вид диверсификации требует наибольших } \\
\text { финансовых затрат }\end{array}$ \\
\hline $\begin{array}{l}\text { Вертикальная (концентри- } \\
\text { ческая, центрированная) }\end{array}$ & $\begin{array}{l}\text { Предусматривает расширение производства путем выпуска продукции пред- } \\
\text { приятия изделиями, которые находятся в одной производственно-технологи- } \\
\text { ческой цепочке с основной продукцией предприятия. Основной целью такой } \\
\text { диверсификации является достижение эффекта синергии и расширение рынка } \\
\text { сбыта продукции. Вертикальная диверсификация осуществлется предприяти- } \\
\text { ем с целью усиления конкурентной позиции своей основной деятельности }\end{array}$ \\
\hline Горизонтальная & $\begin{array}{l}\text { Представляет собой переход к производству нового продукта на основе типо- } \\
\text { вого производственного цикла. Таким образом происходит пополнение ассор- } \\
\text { тимента продукции предприятия товарами, которые не связаны с теми, что } \\
\text { уже им производятся, но могут вызвать интерес потребителей освоенного } \\
\text { предприятием рынка. Такая диверсификация предусматривает выход в новые } \\
\text { сферы бизнеса, которые связаны с удовлетворением дополнительных потреб- } \\
\text { ностей. К горизонтальной диверсификации относят также диверсификацию } \\
\text { рынков (географическое расширение) путем горизонтальных слияний или по- } \\
\text { глощений с целью экспансии на новые рынки, то есть интеграцию }\end{array}$ \\
\hline Сочетает вышеприведенные виды диверсификации
\end{tabular}

Примечание. Разработано автором на основе: [Сафрончук, 2017].

Таблица 5

Классификация видов диверсификации в зависимости от направления деятельности

\begin{tabular}{|l|l|}
\hline \multicolumn{1}{|c|}{ Виды диверсификации } & \multicolumn{1}{c|}{ Особенности } \\
\hline Несвязанного типа & $\begin{array}{l}\text { Предусматривает осуществление новой деятельности, которая не имеет отно- } \\
\text { шения или не связана с основной деятельностью компании }\end{array}$ \\
\hline Связанного типа & $\begin{array}{l}\text { Предполагает новую деятельность, имеющую отношение к уже существую- } \\
\text { щей, которая зависит от нее }\end{array}$ \\
\hline
\end{tabular}

Примечание. Разработано автором на основе: [Сафрончук, 2017]. 
Я.Э. Дадаев. Диверсификация и интеграция как формы обеспечения стратегических ориентиров

ления оптимальных вариантов диверсификации в рамках внедряемой стратегии развития предприятия и стратегических ориентиров управления лежит оценка доходности и риска конкретного выбранного направления, учет стадии жизненного цикла предприятия и его ресурсов.

К факторам внутренней среды предприятия, влияющим на диверсификацию, относятся:

- стратегические (миссия, цель, стратегические ориентиры, задачи);

- экономические (отображаются основными показателями деятельности предприятия - индикаторами рентабельности, финансовой независимости, деловой активности и др.);

- организационно-управленческие (размеры предприятия, организационная структура, организационная форма и др.);

- материально-технические (применяемые технологии, сырье, материалы, комплектующие, производственные мощности, оборудование и др.);

- социальные (знания, умения, навыки, опыт персонала);

- инвестиционно-инновационные (динамика и эффективность размещения и привлечения инвестиций, инновационная активность, готовность к внедрению инноваций и др.).

Также при разработке стратегии диверсификации необходимо учитывать ряд крите- риев: критерий привлекательности отрасли, выбранной для диверсификации; критерий затрат для вхождения в отрасль; критерий дополнительных преимуществ от диверсификации.

В обобщенном виде при диверсификации могут использоваться следующие подходы (см. рисунок).

Диверсификация тесно связана с интеграцией. Понятие «интеграция» рассматривается в отношении различных уровней экономики - предприятий (микроуровень, корпоративный уровень), регионов (мезоуровень), стран (макроуровень), надгосударственных систем управления (мегауровень). Кроме того, сегодня различают экономическую интеграцию, политическую, социальную, финансовую, научно-техническую, производственную, культурную и др.

В научной литературе предлагаются различные толкования понятия «интеграция»:

- объединение экономических субъектов, углубление их взаимодействия, развитие связей между ними [Новый экономический словарь, 2008];

- организационно-экономическое слияние двух или более элементов в единое целое, при котором появляется новое качество; понятие находит свое отражение в синергии интегрированного капитала, где синергия - рост активности деятельности в результате соедине-

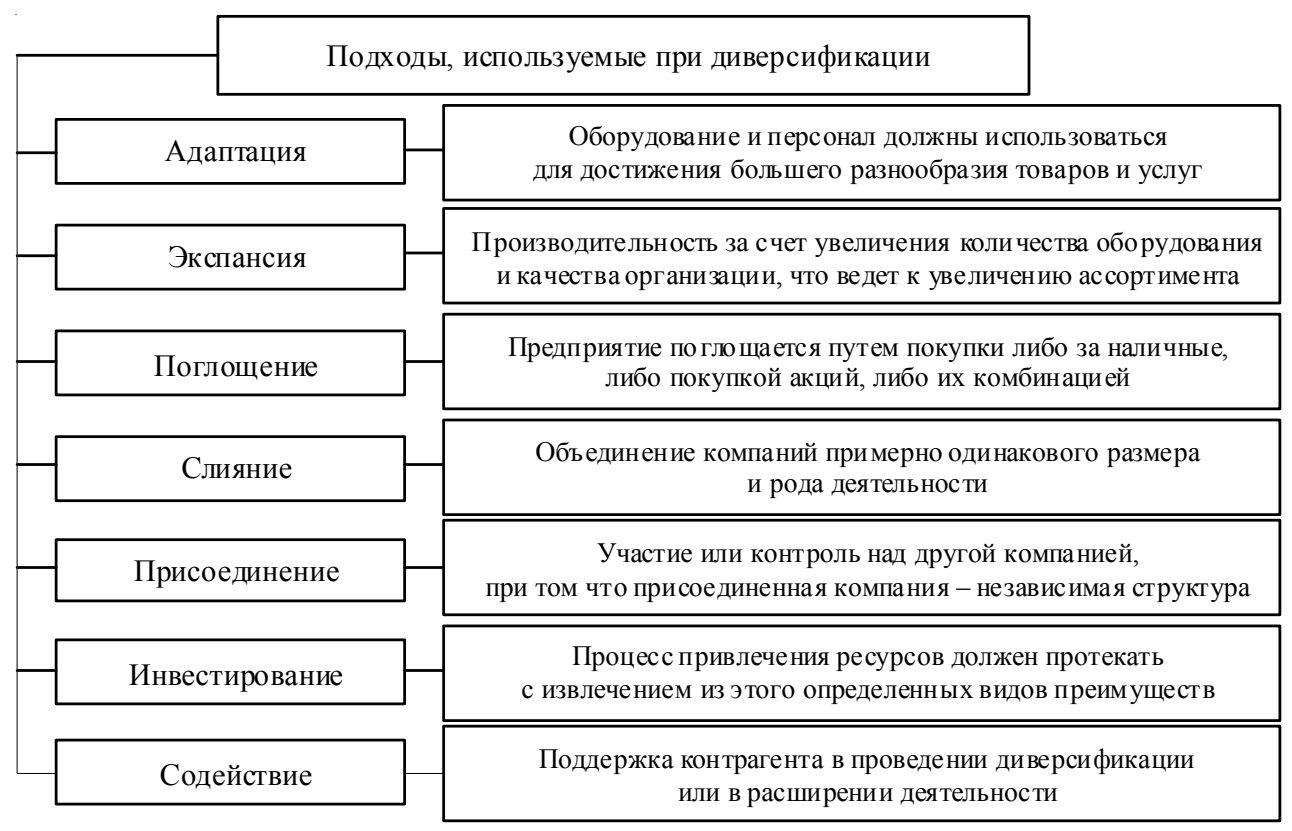

Рисунок. Подходы, используемые при диверсификации предприятий

Примечание. Разработано автором. 
ния, интеграции, слияния отдельных частей в единую систему за счет так называемого системного эффекта [Алешин, 2004];

- организационное сочетание технологически связанных между собой разнородных видов деятельности с присущими им функциями для производства конечного продукта и доведения его до потребителя;

- процесс объединения предприятий с целью устойчивого развития и повышения эффективности деятельности на основе достижения положительного системного эффекта [Федосеев, 2018];

- процесс усиления степени взаимодействия предприятий, что сопровождается установлением между участниками длительных отношений, соединения или согласованности действий [Волкова, 2018].

Следовательно, интеграция рассматривается как:

- процесс объединения различных элементов, экономических субъектов в единое целое;

- процесс углубления взаимодействия и гармонизации отношений между экономическими субъектами на основе сочетания экономических интересов;
- процесс слияния или поглощения экономических субъектов.

В общем виде экономическая интеграция является процессом взаимоотношений между предприятиями (экономическими субъектами), обеспечивающими долгосрочное сближение основных целей предприятий.

Интеграция предприятий может происходить в разных формах (что определяется системой экономических отношений между членами интегрированной структуры): ассоциации, консорциумы, синдикаты, картели, холдинги, концерны, финансово-промышленные группы.

В процессе создания интеграционной структуры обязательно учитывается специфика деятельности всех участников, а также совокупность внешних и внутренних факторов, определяющих особенности функционирования предприятий - участников интеграции.

В основе рассмотренных выше форм интеграции предприятий могут лежать различные виды интеграции (табл. 6).

Диверсификация как вид интеграции распределяется на связанную и несвязанную (конгломератную) диверсифицированность. Связанная диверсификация предполагает разви-

Таблица 6

\section{Виды интеграции предприятий по характеру связей между объектами интеграции}

\begin{tabular}{|c|c|c|}
\hline Виды интеграции & Характеристика & Преимущества \\
\hline Горизонтальная & $\begin{array}{l}\text { Предполагает объединение предприятий, } \\
\text { находящихся на одинаковых этапах произ- } \\
\text { водства, работают и конкурируют в одном } \\
\text { сегменте рынка, в одной отрасли }\end{array}$ & $\begin{array}{l}\text { Увеличение объемов рынка сбыта; расши- } \\
\text { рение масштабов производства; расшире- } \\
\text { ние номенклатуры изделий, экономия на } \\
\text { масштабах производства; рациональное } \\
\text { использование мощностей }\end{array}$ \\
\hline Вертикальная & $\begin{array}{l}\text { Предусматривает объединение предпри- } \\
\text { ятий различных отраслей, связанных тех- } \\
\text { нологическим процессом производства, то } \\
\text { есть расширение предприятием своей дея- } \\
\text { тельности }\end{array}$ & $\begin{array}{l}\text { Экономия в затратах за счет: снижения } \\
\text { удельных затрат на производство и эконо- } \\
\text { мия затрат, связанных с использованием } \\
\text { подрядчиков и посредников; снижение } \\
\text { транзакционных издержек; оперативность } \\
\text { в перераспределении ресурсов между } \\
\text { предприятиями }\end{array}$ \\
\hline Диагональная & $\begin{array}{l}\text { Предполагает объединение предприятий, } \\
\text { находящихся на разных уровнях вертикаль- } \\
\text { ного производственного цикла. Целью диа- } \\
\text { гональной интеграции предприятий являет- } \\
\text { ся влияние на предприятие косвенным об- } \\
\text { разом через связанные с ним производства }\end{array}$ & $\begin{array}{l}\text { Диверсификация рисков; осуществление } \\
\text { давления на конкурентов, потребителей и } \\
\text { поставщиков }\end{array}$ \\
\hline $\begin{array}{l}\text { Диверсификация } \\
\text { (связанная и } \\
\text { конгломератная) }\end{array}$ & $\begin{array}{l}\text { Предполагает объединение предприятий } \\
\text { разных отраслей, технологически между } \\
\text { собой не связанных, в результате чего } \\
\text { предприятия превращаются в сложные } \\
\text { многоотраслевые комплексы }\end{array}$ & $\begin{array}{l}\text { Позволяет избежать части рисков путем } \\
\text { распределения капитала между различны- } \\
\text { ми видами деятельности }\end{array}$ \\
\hline
\end{tabular}

Примечание. Разработано автором на основе: [Федосеев, 2018; Тищенко и др., 2008]. 
тие нескольких видов бизнеса, связанных между собой определенным образом (например, в производстве, маркетинге, материальном снабжении, технологии, продажах и т. п.), и может быть вертикальной или горизонтальной. Несвязанная диверсификация, когда предприятие развивает несколько различных не связанных между собой видов бизнеса. Связанная диверсификация имеет преимущества перед несвязанной из-за того, что предприятие действует в более знакомой обстановке и меньше рискует.

Кроме приведенной классификации интеграции, в научной литературе предлагаются различные классификации в зависимости от определенных классификационных признаков:

- по сфере охвата общественной жизни (экономическая интеграция, политическая, социальная);

- по степени однородности объектов / субъектов интеграции (интеграция однородных (симметричных) объектов / субъектов, интеграция разнородных (асимметричных) объектов / субъектов);

- по уровню иерархии мировых систем (внутрирегиональная интеграция, межрегиональная, международная);

- институциональное строение интеграционных объединений (предприятия, регионы, государства, надгосударственные системы управления, другие институты);

- по объектам интеграции (интеграция ресурсов, интеграция институтов) и др.

Интеграция может происходить как на основе добровольных объединений, так и путем «недружественных», «враждебных» приобретений акций одних предприятий другими или захвата предприятий, в результате чего формируются различные формы и виды интеграции предприятий. В общем, добровольными (дружественными) считаются слияния и приобретения, а поглощения чаще рассматриваются как «враждебные» [Тищенко и др., 2008].

Процессы интеграции на основе слияний и поглощений в российской промышленности особенно активно начались с конца 1990-х годов. Они способствовали оперативной консолидации акционерного капитала и усилению контроля крупных субъектов хозяйствования. «В ряде случаев результат интеграции носит разрушительный характер не только для хо- зяйствующего субъекта - участника, но и для входящих в его состав подразделений. Это происходит, как вследствие стратегических и тактических ошибок хозяйствующих субъектов, так и в результате недостаточно эффективного выполнения функций государством» [Немцев, 2018].

Стоит отметить, что современное корпоративное управление определяет интеграцию как следующий этап развития диверсификации, концентрации, специализации и кооперации производств, хотя процессы диверсификации и интеграции являются нераздельными и связанными. В общем, именно процессы диверсификации, а также потребность в финансовых ресурсах, информационной, правовой, транспортной и иной инфраструктуры привели к значительной интеграции производства во всем мире. Интеграция приводит к более тесному сотрудничеству и кооперации предприятий, углублению взаимодействия между ними и развитию взаимосвязей и в итоге - к объединению экономических субъектов. Итак, диверсификация и интеграция, при их корректном проведении, выступают эффективными механизмами улучшения финансового состояния предприятия, повышения его конкурентоспособности и инвестиционной привлекательности.

Место и роль диверсификации/интеграции в стратегическом управлении можно рассматривать с точки зрения статических характеристик, динамических характеристик и согласно макроэкономическим показателям [Грибанов, 2011].

\section{Выводы}

Усиление внешней и внутренней нестабильности функционирования хозяйствующих субъектов предъявляет новые требования к выбору и обоснованию форм обеспечения стратегических ориентиров управления развитием предприятий, способных обеспечить их жизнеспособность и устойчивое развитие.

Эффективное управление интеграционными и диверсификационными процессами предполагает предварительную формулировку идеи интеграционного проекта с учетом стратегических целей, региональных, отраслевых и других особенностей (в рамках ситу- 
ационного подхода), разработку технологии реализации этого проекта.

На основе проведенного исследования можно сделать выводы, что стратегия является основным инструментом достижения целевых стратегических ориентиров управления развитием предприятия, которые могут быть выражены как количественно, так и качественно. Главным (целевым) ориентиром управления развитием предприятия является обеспечение его жизнеспособности. Достижение этого ориентира требует реализации ряда базовых и специфических ориентиров, которые, вместе с целевым, будут составлять систему стратегических ориентиров. При этом специфические ориентиры должны быть развитием базовых ориентиров в зависимости от миссии предприятия, его структуры, специфики, внешнего окружения и других факторов.

Стратегия любой предпринимательской структуры всегда должна быть динамичной и обновляться по мере ее развития. Потребность в изменениях появляется тогда, когда менеджмент видит пути улучшения существующей стратегии или возникает необходимость привести стратегию в соответствие с новыми рыночными условиями. В этом случае, прежде всего, необходимым является пересмотр стратегических ориентиров управления развитием предприятия, а также форм их обеспечения, среди которых важнейшее место занимают диверсификация и интеграция.

В обобщенном виде диверсификация представляет собой стратегию развития предприятия, что предполагает одновременное вложение капитала в развитие многопрофильного бизнеса. В основе определения оптимальных вариантов диверсификации в рамках внедряемой стратегии развития предприятия и стратегических ориентиров управления лежит оценка доходности и риска конкретного выбранного направления, учет стадии жизненного цикла предприятия и его ресурсов. Также при разработке стратегии диверсификации должен учитываться ряд критериев: привлекательность отрасли; расходы на вхождение в отрасль; дополнительные преимущества от диверсификации и др. Формирование и реализация стратегии диверсификации предприятия предусматривает обоснование выбора ее видов, форм и подходов.
Диверсификация тесно связана с интеграцией. В общем виде экономическая интеграция является процессом таких взаимоотношений между предприятиями (хозяйствующими субъектами), которые обеспечивают долгосрочное сотрудничество. Интеграция предприятий также может происходить в различных формах, в основе которых могут лежать различные виды интеграции.

В процессе создания интеграционной структуры должна учитываться специфика деятельности всех участников, а также вся совокупность внешних и внутренних факторов, определяющих особенности функционирования предприятий - участников интеграции и влияющих на выбор формы интеграции.

Выбор диверсификации или интеграции как форм обеспечения стратегических ориентиров управления развитием предприятий должен базироваться на учете целого ряда критериев целесообразности реализации определенной стратегии.

В целом диверсификация и интеграция являются важнейшими инструментами роста эффективности функционирования предприятий, направленного на повышение их жизнеспособности и конкурентоспособности, улучшение финансового состояния и инвестиционной привлекательности.

\section{СПИСОК ЛИТЕРАТУРЫ}

Алешин, М. Интеграция фиктивного и реального капитала в финансово-промышленных группах и холдингах / М. Алешин // Маркетинг. 2004. - № 3. - С. 17-27.

Ансофф, И. Стратегическое управление / И. Ансофф. - М. : Экономика, 1989. - 519 с.

Боссель, Х. Показатели устойчивого развития: теория, метод, практическое использование. Отчет, представленный на рассмотрение Балатонской группы / Х. Боссель. - Тюмень : Изд-во ИПОС СО РАН, 2001. - 123 с.

Волкова, Ю. А. Интеграция промышленных предприятий Республики Беларусь: методическое обеспечение выбора форм и оценки эффективности : автореф. дис. ... канд. экон. наук / Волкова Юлия Александровна. - Минск, 2018. $-27 \mathrm{c}$.

Грибанов, А. В. Интеграция и диверсификация в стратегии развития предпринимательской структуры / А. В. Грибанов // Научно-техни- 
ческие ведомости СПбГПУ. Серия «Экономические науки». - 2011. - № 4. - С. 254-258.

Ерохина, Е. А. Развитие национальной экономики: системно-самоорганизационный подход : дис. ... канд. экон. наук / Ерохина Елена Анатольевна. - Томск, 2000. -414 с.

Концепты. Гуманитарный портал. - Электрон. текстовые дан. - Режим доступа: https:/gtmarket. ru/concepts (дата обращения: 13.11.2020). Загл. с экрана.

Мескон, М. Основы менеджмента / М. Мескон, М. Альберт, Ф. Хедоури. - М. : Дело, 2006. $720 \mathrm{c}$.

Немцев, В. Н. Теоретические аспекты формирования систем управления интеграционными процессами в современной экономике / В. Н. Немцев // Корпоративная экономика. 2018. - № 1 (3). - С. 4-15.

Новый экономический словарь. - М. : Омега-Л, 2008. $-1088 \mathrm{c}$.

Сафрончук, М. В. Стратегии выживания: диверсификация производства, дифференциация продукта и их последствия / М. В. Сафрончук // Проблемы управления. - 2017. - № 5 (1). С. 73-78. - Электрон. текстовые дан. - Режим доступа: https:/mgimo.ru/upload/iblock/e63/ safronchuk.pdf(дата обращения: 14.11.2020). Загл. с экрана.

Стратегия - понятия и определения. Классификация стратегий // Стратегическое управление и планирование. - Электрон. текстовые дан. Режим доступа: http:/www.stplan.ru/articles/ theory/strategy.htm (дата обращения: 14.11.2020). - Загл. с экрана.

Стрелков, М. А. Управление диверсификацией предпринимательской деятельности российских корпораций : автореф. дис. ... канд. экон. наук / Стрелков Михаил Анатольевич. - М., 2008. - 18 c.

Тищенко А. Н. Понятийный аппарат в интеграционных процессах слияний и поглощений компаний / А. Н. Тищенко, В. Е. Хаустова // Бизнес Информ. - 2008. - № 12 (1). - С. 78-90.

Федосеев, А. В. Основы менеджмента : монография / А. В. Федосеев. - Челябинск : Изд-во ЮУрГГПУ, 2018. - 160 с.

Pareto, V. Traiffi de sociologie gimurale: Oeuvres com-c plntes / V. Pareto // Geimve. - 1968. Vol. 84, № 4. -639 p.

\section{REFERENCES}

Aleshin M. Integracija fiktivnogo i real'nogo kapitala $\mathrm{v}$ finansovo-promyshlennyh gruppah i holdingah [Integration of Fictitious and Real
Capital in Financial and Industrial Groups and Holdings]. Marketing [Marketing], 2004, no. 3, pp. 17-27.

Ansoff I. Strategicheskoe upravlenie [Strategic Management]. Saint Petersburg, Ekonomika Publ., 1989. 519 p.

Bossel' H. Pokazateli ustojchivogo razvitija: teorija, metod, prakticheskoe ispol'zovanie. Otchet, predstavlennyj na rassmotrenie Balatonskoj gruppy [Indicators of Sustainable Development: Theory, Method, Practical Use. Report Submitted to the Balaton Group]. Saint Petersburg, Izd-vo IPOS SO RAN, 2001. 123 p.

Volkova Ju.A. Integracija promyshlennyh predprijatij Respubliki Belarus': metodicheskoe obespechenie vybora form $i$ ocenki jeffektivnosti: avtoref. dis. ... kand. ekon. nauk [Integration of Industrial Enterprises of the Republic of Belarus: Methodological Support for the Choice of Forms and Performance Evaluation. Cand. econ. sci. abs. diss.]. Minsk, $2018.27 \mathrm{p}$.

Gribanov A.V. Integracija i diversifikacija v strategii razvitija predprinimatel'skoj struktury [Integration and Diversification in Business Development Strategies]. Nauchnotehnicheskie vedomosti SPbGPU. Serija «Jekonomicheskie nauki» [St. Petersburg State Polytechnical University Journal. Economics], 2011, no. 4, pp. 254-258.

Erohina E.A. Razvitie nacional'noj jekonomiki: sistemno-samoorganizacionnyj podhod: dis. ... kand. ekon. nauk [Development of the National Economy: A System-Self-Organizational Approach. Cand. econ. sci. diss.]. Tomsk, 2000. $414 \mathrm{p}$.

Koncepty. Gumanitarnyj portal [Concepts. Humanitarian Portal]. URL: https:/gtmarket.ru/ concepts/ (accessed 13 November 2020).

Meskon M., Al'bert M., Khedouri F. Osnovy menedzhmenta [Basics of Management]. Moscow, Delo Publ., 2006. 720 p.

Nemcev V.N. Teoreticheskie aspekty formirovanija sistem upravlenija integracionnymi processami v sovremennoj jekonomike [Theoretical Aspects of the Formation of Management Systems for Integration Processes in the Modern Economy]. Korporativnaja jekonomika [Corporate Economy], 2018, no. 1 (3), pp. 4-15.

Novyj jekonomicheskij slovar' [New Economic Dictionary]. Moscow, Omega-L Publ., 2008. $1088 \mathrm{p}$.

Safronchuk M.V. Strategii vyzhivanija: diversifikacija proizvodstva, differenciacija produkta $\mathrm{i}$ ih posledstvija [Survival Strategies: Diversification of Production, Product Differentiation and Their 


\section{УПРАВЛЕНИЕ ЭКОНОМИЧЕСКИМ РАЗВИТИЕМ}

Consequences]. Problemy upravlenija [Management Problems], 2017, no. 5 (1), pp. 7378. URL: https://mgimo.ru/upload/iblock/e63/ safronchuk.pdf/ (accessed 14 November 2020). Strategija - ponjatija i opredelenija. Klassifikacija strategij [Strategy - Concepts and Definitions. Classification of Strategies]. Strategicheskoe upravlenie i planirovanie [Strategic Management and Planning]. URL: http://www. stplan.ru/ articles/theory/strategy.htm/ (accessed 14 November 2020).

Strelkov M.A. Upravlenie diversifikaciej predprinimatel'skoj dejatel'nosti rossijskih korporacij: avtoref. dis. ... kand. ekon. nauk
[Business Diversification Management for Russian Corporations. Cand. econ. sci. abs. diss.]. Moscow, 2008. 18 p.

Tishhenko A.N., Khaustova V.E. Ponjatijnyj apparat v integracionnyh processah slijanij i pogloshhenij kompanij [Conceptual Framework in the Integration Processes of Mergers and Acquisitions of Companies]. Biznes Inform [Business Inform], 2008, no. 12 (1), pp. 78-90.

Fedoseev A.V. Osnovy menedzhmenta: monografiya [Management Basics. Monograph]. Chelyabinsk, Izd-vo YuUrGGPU, 2018. $160 \mathrm{p}$.

Pareto V. Traiffi de sociologie gimurale: Oeuvres com-c plntes. Geimve, 1968, vol. 84, no. 4.639 p.

\section{Information About the Author}

Yakub E. Dadaev, Senior Lecturer, Department of Economic Theory and Entrepreneurship, Chechen State University, A. Sheripova St, 32, 364024 Grozny, Russian Federation, dadaev.ya.82@mail.ru, https://orcid.org/0000-0002-8439-3360

\section{Информация об авторе}

Якуб Элхазурович Дадаев, старший преподаватель кафедры экономической теории и предпринимательства, Чеченский государственный университет, ул. А. Шерипова, 32, 364024 г. Грозный, Российская Федерация, dadaev.ya.82@mail.ru, https://orcid.org/0000-0002-8439-3360 